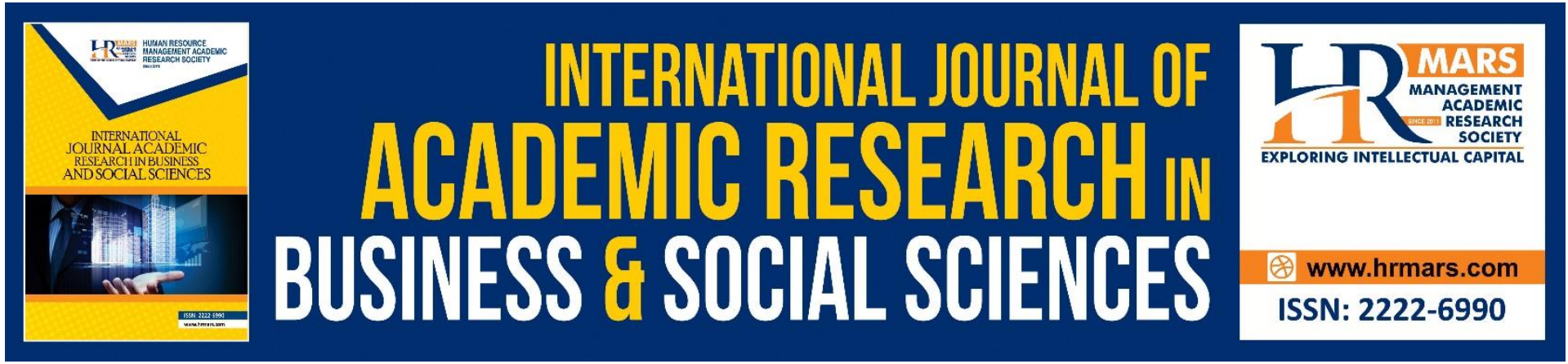

\title{
The Use of Sing along Song in the learning of the Possessive Adjective and Possessive Pronoun
}

\section{Nurnadirah binti Khairul Annuar Asya'ari, Melor Md Yunus}

To Link this Article: http://dx.doi.org/10.6007/IJARBSS/v11-i6/10244

DOI:10.6007/IJARBSS/v11-i6/10244

Received: 16 April 2021, Revised: 22 May 2021, Accepted: 04 June 2021

Published Online: 17 June 2021

In-Text Citation: (Asya'ari \& Yunus, 2021)

To Cite this Article: Asya'ari, N. binti K. A., \& Yunus, M. M. (2021). The Use of Sing along Song in the learning of the Possessive Adjective and Possessive Pronoun. International Journal of Academic Research in Business and Social Sciences, 11(6), 1154-1164.

\section{Copyright: (C) 2021 The Author(s)}

Published by Human Resource Management Academic Research Society (www.hrmars.com)

This article is published under the Creative Commons Attribution (CC BY 4.0) license. Anyone may reproduce, distribute, translate and create derivative works of this article (for both commercial and non-commercial purposes), subject to full attribution to the original publication and authors. The full terms of this license may be seen at: http://creativecommons.org/licences/by/4.0/legalcode

Vol. 11, No. 6, 2021, Pg. 1154- 1164

Full Terms \& Conditions of access and use can be found at http://hrmars.com/index.php/pages/detail/publication-ethics 


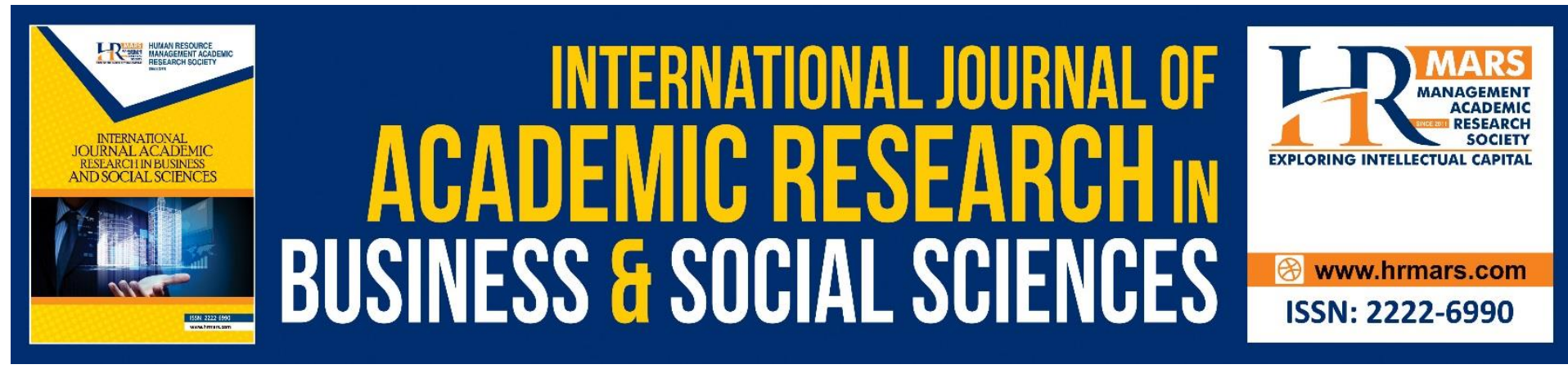

\title{
The Use of Sing along Song in the learning of the Possessive Adjective and Possessive Pronoun
}

\author{
Nurnadirah binti Khairul Annuar Asya'ari ${ }^{1}$, Melor Md Yunus ${ }^{2}$ \\ ${ }^{1}$ SK Nanga Oyan, D/A PPD Kapit, 96800 Kapit, Sarawak, ${ }^{2}$ Faculty of Education, Universiti \\ Kebangsaan Malaysia (UKM), 43600 Bangi, Selangor, Malaysia
}

\begin{abstract}
The pupils at a rural school were struggling to master the usage of Possessive Adjective and Possessive Pronoun .This action research was done to improve the usage of the Possessive adjective (PA) and Possessive pronoun (PP) among the pupils of a rural school with the use of the sing along song. This action research involved 16 year 4 low proficiency pupils of a rural school. The data was collected by using the test score of their pretest, post test and structured interview.This action research adopt the Kemmis and Mctaggart cyclic process.The finding shows that the sing along song helped in improving the usage of Possessive Adjective and Possessive Pronoun among the pupils. The pupils retain the improvement in their ability to identify and differentiate each types of the pronouns when the pupil's score increase in their post test and also in their score for the second interview.
\end{abstract}

Keywords: Pronoun, Sing Along Song, Possessive Adjective, and Possessive Pronoun

\section{Introduction}

The widespread of the pandemic,Covid 19 all throughout the world has changed the norm of lives. The school has been closed down in order to break the chain of the spreading. Although there has been a decline in the number of cases in the country the situation continues to be alarming and safety precautions continues to be taken seriously (Yusof, 2020). These situation has sent the teacher to a new norm of teaching which is the Home-Based learning (Rajaendram, 2020). In which the learning is made digital. However, pupils at the rural area are known nationwide as pupils with less exposure to the modernization.Located in the area covered with thick jungle, the people of the rural area still living their lives with the old ways. The coverage of the communication signal has yet to reach their part therefore, the internet is completely unavailable in the area. This condition has create a big gap between the pupils of the rural area and the pupils in the urban area. The gap has inspired educators to innovate various ways of teaching and learning in order to suit the needs of the pupils learning. Although it is unable to involve any digitalize media but the pupils are not left behind in this motion of the Home-Based Learning.

The year 4 pupils has been discovered to have struggle to understand the grammar items of the PA (Possessive Adjective) and PP (Possessive Pronoun). Contributing to that problem was the less interaction they had with their English teacher since the mid term of the year,due to the Covid 19.Then, the pupils were sent home following the order of the government to 
close down the school due the increasing numbers of infected cases across the country. The pupils of the rural area were accustomed to learn with the presence of their teacher. Therefore, the thought of them not be able to grasp the concept of the grammar items has been a constant concern of the researcher. The pupils were about to enter their year 5 and these grammar items must be taught to them as each PP and PA are high frequency types of words. They need to know the usage of it in order to understand the whole sentence where it is being used. In order to do so, the researcher has came up with an approach to teach these grammar items without the need to drill the pupils. This approach would be suitable to be used as one of the Home Based Learning activity to improve their learning on the PA and PP in a short amount of time. The chosen approach was a Sing Along Song.

\section{Background of the Study}

In the learning of English the teaching is apparently in depth due to the fact that English is not the first language in this country, it is considered as the second language. To the pupils of the rural area, English is not their second language nor it is their third , provided that the rural area consist of pupils of different ethnicity background, such as those pupils in the east part of the country. Therefore, the pupils are also known to be struggling in the learning of the targeted language.The struggles of the pupils in learning English is much contributed to the fact that they do not converse in the language in their daily lives. This situation has become an obstacle in their learning of grammar rules.Possessive Adjective and Possessive Pronoun are one of the grammar rule that has to be taught to the pupils as they enter the second level of their primary schooling. They have started to learn grammar explicitly when they enter level 2, which are the Year 4, 5 and 6. The grammar are taught in the level 1, however not too explicitly.Possessive Adjective is a type of adjective that is used to show ownership.It comes before a noun and act as an indication as to whom the noun belongs to (Soft schools, 2020). PA is use to imply a person's possession over something,however PP does not accompany by noun when it is used in a sentence, while PA is used prior to the noun which usually refer to the item that belongs to a person (Milne, 2019). Apparently, this concept of PA and PP were difficult for the pupils to understand because in their first language which is Iban language uses only one pronoun "iya" to refer to the belongings of a person regardless of the plural and singular and also their gender.

When the CEFR (Common European Framework of Reference for Languages) adapted and implemented in the Malaysia's English curriculum standard, the English language started focusing on making the learning of English more communicative (Uri \& Aziz, 2018).In order to train the pupils to use English correctly in communicative way, they have to be equipped with a strong basic of correct English usage from their elementary level. In the year 4 English Curriculum Standard the learning standard of the grammar is stated accordingly in content standard. It is stated that,by the end of the 6 year primary schooling, pupils will be able to use different word classes correctly and appropriately (Sistem Guru Online, 2019).In a nutshell, the rules of grammar guided the user in using English to converse with appropriate manner in order to convey the meaning in the correct words, phrases and sentences. In order to make sure that this aim is achieved the pupils have to be equipped with a strong hold on grammar rules.In this research, to help the pupils to properly use PA and PP, the pupils were approached with a technique that adhere to their needs in learning, which was the sing along song. This approach has led to this research objective and the research question, which were

1. Research Objective:To improve the PA and PP usage among the pupils by using the Sing Along Song. Research 
2. Question:How the sing along song helps in improving the PA and PP usage among the pupils?

\section{Literature Review}

\section{A. Grammar teaching and learning}

Grammar is define as a rules of a language governing the sounds, words, sentences, and other elements, as well as their combination and interpretation (The Editors of Encyclopaedia Britannica,2020). In short every language has the set of rule to make the language more properly spoken and used. In English language, grammar is define as set of rules that encompass syntax which is the way in which words are arranged to create phrases,clauses and also morphology the focus on word structures (Kid Sense, 2016).As a country that adopt English as a Second Language it is important that the language is learn correctly in order to convey the right meaning. The lack of the grammar skill contribute to poor writing when the pupils enter the next level of study.Carnegie Mellon University listed down that poor grammar and syntax leads to unclear organization, weak reasoning and arguments(Why Are Students Coming into College Poorly Prepared to Write?, n.d.). Supporting the statement is a study done by Dr. Pradeep Kumar Debata on the importance of grammar concluded that it is difficult for a person to learn English accurately only through a process of assimilation for grammar acts as a ground reference if a person encounter problems with understanding English (Debata,2013). Therefore, grammar is importance in learning English as it is the fundamental essence to a good English language user.

The teaching of grammar can be taught explicitly and implicitly. Explicit teaching of grammar is a direct method in explaining the rules to the learners, whereas when the grammar is taught implicitly the learners are presented with the ways to acquire the language based on comprehensible input without too much focus on grammar input (Rhalmi, 2020) . Apart from that,without realizing it, the grammar is taught explicitly in our Malaysian context of English teaching. Azli \& Akmar (2019) also claimed the same statement,in which the teachers are still favoring the conventional teaching of directly from textbook in teaching English and less preferred self-materials, one of the component that are taught in the particular way is grammar. However, the conventional teaching of direct grammar input to the learners should not be set aside as educators depend solely on their pupils performances in choosing their own way of teaching. Most common method and still relevance used by the teachers in Malaysia in conventional teaching is the Grammar translation method (UKEssays, 2018). Study done by Cagri Tugrul Mart showing that the use of grammar translation contributes to the use of the target language effectively (Mart,2013). Learning gets meaningful via translation, and better comprehension promotes foreign language proficiency. As a conclusion, grammar should be taught in details to the learners in order to produce a proficient English user.In the end,the point to concern is the way to present the input to the learners without appearing to be drilling them.

\section{B. Sing Along Song}

The use of song is no longer taught in Music subject alone. Songs has been integrated in learning of language over a decades ago. In the English Curriculum itself song is listed in one of the learning standard under the Language Arts (Sistem Guru Online,2019). Noor Arina Nadiah Abdul Razak \& Melor Md Yunus in their research discovered that using action song improve the learners vocabulary acquisition mainly in action words (Razak et al.,2016). Supporting the research,another study was proven to increase vocabulary acquisition among English language learners at tertiary level with the use of songs is able to provide a fun way 
of picking up new words (Zamin et al., 2020). In addition, incorporating song is affordable,the educators are not require to be in a training to involve song in the teaching.Incorporating song in teaching of an in depth input such as the grammar is much encouraging as the song proven to ease the learning.

A study done on The Impact of Using music and songs on teaching EFL (English as A Foreign Language) in China by non-native English teachers concluded that songs has numerous impact on the learning. Such impact was, it was a solution for the learners with the problems to learn by establishing a connection between the learners and the teacher. The song was also claimed to fit the social-psychological function and strengthens the groups dynamics. Apart form that it was also claimed that the song lowers the affective filter of the learners as the song shifted their focused to give attention towards the teacher when the song was integrated in the learning (Vishnevskaia \& Zhou, 2019 ). Kara \& Aksel (2013) conducted a study to determine the effectiveness of music in grammar teaching on elementary students in foreign schools at Uludag University received positive feedback from the students on the involvement of song in grammar learning. Quoting their respondent by stating grammar learning was drilled to them and repetitively memorizing the same rule until they grasp the concept which was completely monotonous and motivation killer. The integration of the songs in the grammar learning has create diversities and variation in the lesson and improve the environment of the grammar teaching into a fun and exciting lesson. Therefore,although the learning of grammar needed to be taught explicitly by drilling them with the input, it can be made fun with the involvement of song.

\section{Methodology}

\section{Research Design}

The design suitable for this research is action research. Action research is chosen because it is common in language teaching and learning as it involves the practitioners to plan strategies in response to problems related to classroom management,teaching materials and language skills (Jeremy Koay, 2020). This action research is a qualitative research and adapting the cyclic research process by Kemmis and McTaggart (1988), this cyclic process is suitable to measure the effectiveness of a practice on a learning (Gogus, 2012).

\section{Participants}

The participants were 16 year 4 pupils of lower proficiency. They were 6 female and 10 male pupils in the class. All of them came from the local long houses in the rural area. Geographically, their long houses is located quit a distant away from urbanization.These indicates that they received little exposure of the targeted language making it hard for them to achieve at least average or intermediate level for their School-Based Assessments. Apart from that , the pupils lived 3 long houses apart which was less than 15 minutes away from the school and was convenient for the researcher to visit in order to obtain data. The trait that makes them suitable to be approached with the sing along song was that,they have interest in music. The pupils were able to sing songs that were in the first language,lban and the second language,Malay.Their ability to achieve this certain interest was knowingly done by listening and sing along to Iban and Malay song played during the school event. It was also discovered that the pupils learn to sing the songs from their surrounding influences. Those 
influences were said to be from their sibling's music playlist in the mobile phone, and occasionally from their neighbors that sings karaoke on the afternoon.

E. Data Analysis and Data Collection Techniques

The collection of data were done by using pretest, post test and structured interview. The data collected from the pretest and the post test were analyzed by using the Statistical Packages for Social Sciences (SPSS) version 23. The pretest and the post test were written test consist of 20 questions. Each 20 questions represent 20 nouns, each noun was accompanied with the Malay translation in parentheses. Each question requires the pupils to write 5 sentences about the noun by using any of the PA and PP provided correctly. Each correct sentence earn them one mark,therefore the total marks for the test is 100 marks. The structured interviewed consist of 7 questions, and it was done individually in order to elicit the pupil's own answer without the distraction and influences from their peers. The interview was structured in order to perceive the effect of the sing along song on the pupil's way of using the PA and PP. The answers that were expected from the pupils must include the correct usage of the PA and PP in one answer, the answer comprises of 2 sentences, the first sentence used PA and the second sentence used PP. Example of the question was "Whose pencil is this?" , and the expected answer was "It is my pencil. It is mine."The questions and the answers were all in the same sentence pattern as the pattern were taught and repetitively sang with them during the intervention of the sing along song. The example of the questions for the test and the structured interview are as follows :

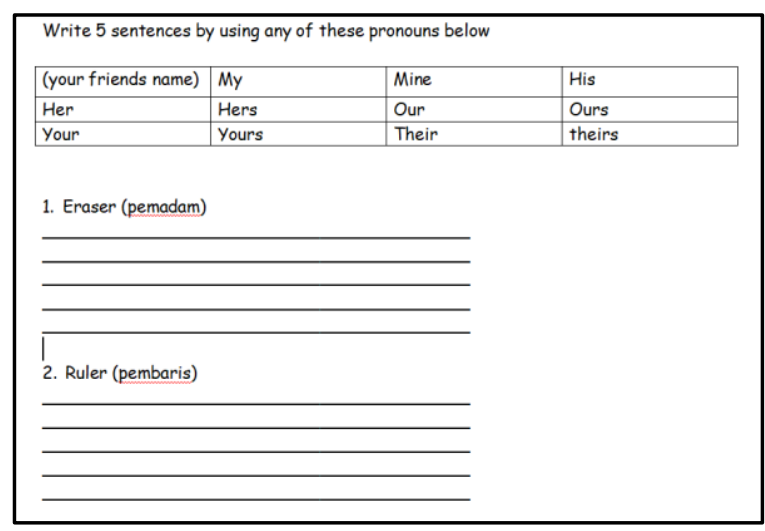

Picture 1 : Example of Questions for the Pretest and Post test

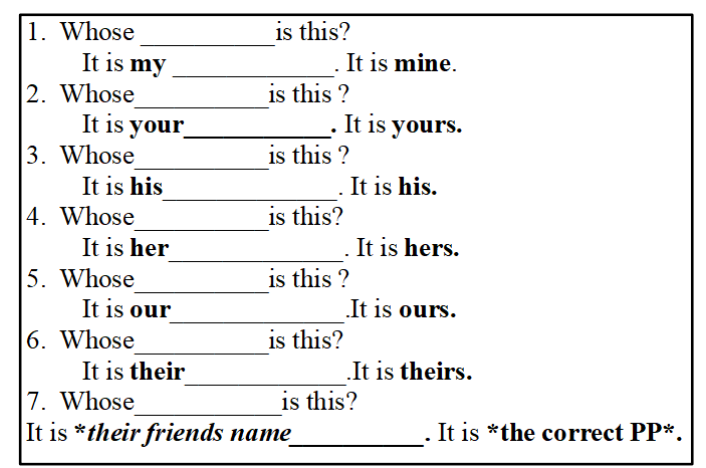

Picture 2: The Structured Interview Questions

As in the picture, the blanks in the questions and in the answers were filled in with 20 nouns that were sang in the song. The nouns included all the pupil's belongings and things from their 
surroundings.The nouns were,eraser, pencil, book, glue, sharpener, table, ruler,watch, pencil case, pants, hairband, spoon, stapler, towel, sandal, comb, blanket, cup, sock, and shoe.

F. Procedure

In the beginning of this research, the pretest was conducted in order to obtain the mean score. The mean score then compared with the mean score of the post test in order to look for inclination on the pupils marks before and after the intervention of the sing along song. During the first cycle of the research,the pupils were introduced to the PA an d PP concept and followed by the song. The song then were practiced with them for two weeks, then they were all interviewed on the last day of the second weeks. Then the marks obtained from the interview were calculated to be compared with the second interview on the second cycle. The sing along activity was continue with them for another two weeks .The post test then conducted on the next week followed by the interview again.

There was only one song that was used and it was accompanied with live keyboard performance by the researcher. The rational behind the live musical instrument was to attract the pupils attention,apart from that,it was to ensure that the pupils sing with the right beats to the song.It is crucial that the pupils sing along together with the right beat. It would be hard to consider the activity as a 'singing along' when a part of the singer were off beat,therefore it is important to reach the synchronization while singing along with the others. Fortunately,it was easier to ensure that students learn the song in a short amount of time by using live music instruments. The song for the sing along song comprises of 10 sentences for each line of the lyrics. They were six possessive adjective sentences, and four possessive pronoun sentences.The song lyrics were as follows:

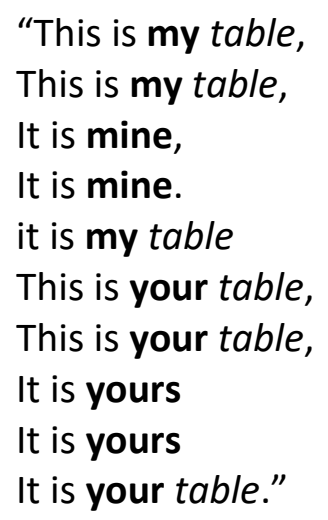

The lyrics in the bold were the PP and the PA, they were changed throughout the course of the singing. They were my,mine,your,yours, her, hers, his, their,theirs,our, ours, and the name of their friends. The nouns were exchangeable to over 20 nouns that were already chosen. The important steps in the procedure, was the presentation of the song to the pupils,the singing along needed to be sang with live music background.Another rational behind the live musical performance accompanying the singing along was because the song needed to be played into three speeds, slow,medium and fast. The speed was important in order to ensure the pupil's attention stay focused in the environment of the singing along. The pupils were known to have short attention span, therefore such approach was needed. As for the structured interview, the items of the 20 nouns were taken in advance from their own belongings and were used during the interview. The items used were the items that can be carried around and also belongs to the pupils,such as the pencil,eraser,pencil case,books,glue, sharpener and stapler. The items must be the items that were recognizable 
to the pupils. The rational of using their own belongings was the items would revive their memory on who the items belongs to therefore would elicit their knowledge on which PP and PA suitable to be used in order to talk about the owner of the items.

\section{Findings and Discussion}

The findings on the pretest and the post test and also structured interview score were obtain in order to answer the research question and to achieve the research objective on improving the pupils usage in PP and PA by utilizing the sing along song in the learning. The mean score of the pupil's score for the structured interview and the pretest and the post test were recorded in table 1 and table 2.

Table 1: The mean score and standard deviation of the Pretest and the Post test

\begin{tabular}{ccc}
\hline & Pretest & Post test \\
\hline Mean & 16 & 39.7 \\
Std.Deviation & 12.1 & 20.9 \\
\hline & Cycle 1 & Cycle 2 \\
\hline & 1.87 & 4.6 \\
Mean & 1.30 & 2.17 \\
\hline
\end{tabular}

Table 2 : The Score of the Structured Interview

From Table 1 it is visible that the post test mean score is higher that the pretest mean score. The pretest mean score is $M=16$ with the standard deviation of $S D=12.1$, it indicates that the pupil's average scores disperse around the mean score which also indicates that the pupils scored almost the same marks. From Table 2 ,their interview score for the Cycle 1 showing the same pattern,the standard deviation of the interview is SD=1.30 and disperse around the mean score as well, which was $M=1.87$. From these score it can be concluded that the pupils shared the same level of the usage on the PA and PP, nevertheless there were significant development on the pupil's score on the post test and their Cycle 2 interview. The post test mean score is $M=39.7$ with the standard deviation of $S D=20.9$, the $S D$ value is larger than the previous SD value which indicates that there were variety of scores obtain by the pupils,although not most of them scored high marks their marks still shows significant increase then their previous score. The pupil's score in their interview for the Cycle 2 also showing a large value of $S D=2.17$ with the mean score of $M=4.6$, it indicates that the pupil's score disperse less concentrated to the mean score, which here means each pupil's score were different from each others.

Analyzing the findings, despite singing and learning the song together during the sing along song activity,the pupils improved and their marks increased with variety of score. It can be concluded that the integration of the sing along song in the learning of the PA and PP helped to develop the pupils skills in using the grammar items correctly, hence it compliments the research objective.The song for the sing along, was simple and repetitive, provided that the lyrics were the exact sentence pattern that the pupils needed to master. Plus,it was accompanied with live musical performances. It can also be seen by the scores on the pupils interview. The pupils scored more marks for their second interview indicating that the pupils were able to use the PP and PA correctly based on the questions that were asked to them. As it was a structured interview, the pupils were able to answer with the expected answer which 
was the exact sentence pattern from the song lyric,showing that the pupils were able to use PA and PP correctly and accordingly. Therefore, these findings answered the research question on "How the sing along song helps in improving the PA and PP usage among the pupils?". The song helped as the pupils were able to follow the repetitive lyrics in which the PA and PP were able to be substituted with other PA and PP,together with the nouns that were involved. It created more choices of words, hence the pupils were able to practice it with the items of PA ,PP and the nouns that were desirable to them.

\section{Conclusion}

The pupils showed significant improvement in using the PA and PP despite being taught explicitly. The involvement of the sing along song helped in improving their usage by allowing them to take control over their own learning, making the learning contextualized without even realizing it.The researcher only needed to provide them with the input but not appearing to be drilling them with it. The lyrics of the song itself was the input and the pupils acquiring it with motivation as they were accompanied with the live musical instrument. In addition, the rhythm of the song keeps them in the learning for it was played into three different speed. The speed influenced them to be alert with the lyrics of the song triggering their cognitive process, therefore, the lyrics were easily implanted in their mind. It was proven when the pupils were able to score more during their interview on the second cycle by answering the interview with the expected answer. Being the learners of a foreign language the pupils were still able to converse during the interview regardless of the structured questions. The fix sentence pattern that were taught to them contributed largely in their way of answering by using the PP and PA of their own choice. In a nutshell, the sing along song does help the pupils to improve their ability to use the PA and PP correctly.

The song not only proven to be improving the pupils usage of the PA and PP but also their motivations. The song contributed essentially in their interest towards the learning of the grammar in a stress free environment. English language acquisition is known to be difficult to be put in a smooth progression,especially for lower proficiency types of pupils (Figueroa,2019). It is common for their affective filter to rise,due to the low motivation in the learning of the language particularly grammar skills. Therefore, the song contributed significantly in assisting their grammar learning by making the learning of the grammar into a fun engaging environment which helped in lowering their affective filter hence their learning of the grammar become smooth. With this significant success of improvement, the school's English panel has added the song as one of the teaching aids for future usage and for further research.

\section{References}

Azli, N., \& Akmar, A. (2019). Implementation of cefr-aligned assessment tools in Malaysian esl classroom. Asia Proceedings of Social Sciences, 4(2), 7-

10. https://doi.org/10.31580/apss.v4i2.688

Mart, C. T. (2013). (2013). The grammar-translation method and the use of translation to facilitate learning in ESL classes.

ResearchGate. https://www.researchgate.net/publication/329268068_The_GrammarTranslation_Method_and_the_Use_of_Translation_to_Facilitate_Learning_in_ESL_Cla sses

Carnegie Mellon University. (2020). Why are students poorly prepared to write - Eberly center - Carnegie Mellon University. CMU - Carnegie Mellon 
University. https://www.cmu.edu/teaching/designteach/teach/instructionalstrategies /writing/poorlyprepared.html

Debata, P. K. (2013). The Importance of Grammar in English Language Teaching - A Reassessment. http://languageinindia.com/may2013/pradeepgrammarfinal.pdf

The Editors of Encyclopaedia Britannica. (2020). Grammar. Encyclopedia Britannica. https://www.britannica.com/topic/grammar

Gogus, A. (2012). Action Research on Learning. Encyclopedia of the Sciences of Learning. Springer, Boston, MA, (2012). https://doi.org/10.1007/978-1-4419-1428-6

Koay,J. (2020, November 7). What is action research? EduMaxi | Educational Product Design \& Development. https://www.edumaxi.com/what-is-action-research/

Kid Sense. (2016). Using grammar. Kid Sense Child Development. https://childdevelopment.com.au/areas-of-concern/usingspeech/using-grammar

Milne, M. (2019). Possessive adjectives and pronouns. Wall Street English. https://www.wallstreetenglish.com/blog/possessive-adjectives-pronouns/

Uri, F., \& Aziz, S. (2018). Implementation of CEFR in Malaysia: Teachers' awareness and the Challenges. 3L: The Southeast Asian Journal of English Language Studies, 24(3), 168183. http://doi.org/10.17576/3L-2018-2403-13

Rhalmi, M. (2020). Inductive and deductive approaches to grammar teaching. My English Pages. https://www.myenglishpages.com/blog/inductive-and-deductive-approaches/

Razak, N. A., \& Yunus, M. M. (2016). Using Action Songs in Teaching Action Words to Young ESL Learners. International Journal of Language Education and Applied Linguistics (IJLEAL), 4, 15-24. http://ijleal.ump.edu.my

Figueroa, R. (2019). Is the affective filter blocking instruction? Ensemble Learning - Together we grow strong schools. https://ensemblelearning.org/is-the-affective-filter-blockinginstruction/

Sistem Guru Online. (2019). DSKP Semua mata pelajaran KSSR (Semakan 2017) Tahun 4. https://www.sistemguruonline.my/2019/02/dskp-semua-mata-pelajaran-kssrsemakan-2017-tahun-4.html

Soft schools. (2020). Possessive adjectives versus possessive pronouns examples. Free Math worksheets, Free phonics worksheets, Math Games and Online activities and Quizzes. https://www.softschools.com/examples/grammar/possessive_adjectives_ver sus_possessive_pronouns_examples/82/

The Editors of Encyclopaedia Britannica. (2020). Grammar. Encyclopedia Britannica. https://www.britannica.com/topic/grammar

Rajaendram, R. (2020). Back to home-based learning. The Star Online. https://www.thestar.com.my/news/education/2020/11/01/back-to-homebased-learning

UKEssays. (2018). Grammar translation relevance in Malaysian classroom cultural studies essay. UKEssays.com. https://www.ukessays.com/essays/cultural-studies/grammartranslation-relevance-in-malaysian-classroom-cultural-studies-essay.php?vref $=1$

Vishnevskaia, M., \& Zhou, Z. (2019). The impact of using music and songs on teaching EFL in China by non-native English teachers. Universal Journal of Educational Research, 7(8), 1808-1813. https://doi.org/10.13189/ujer.2019.070819

Yusof, A. (2020). Malaysia's recovery movement control order extended to Dec 31, tourists still not allowed in: PM Muhyiddin. 
CNA. https://www.channelnewsasia.com/news/asia/malaysia-recovery-movement-controlorder-extended-dec-31-mco-13047724

Zamin, A. A., Mohamad, M., \& Adzmi, N. A. (2020). Learning vocabulary through songs: A study on the role of music in teaching verbs. Humanities \& Social Sciences Reviews, 8(1), 550-557. https://doi.org/10.18510/hssr.2020.8167 